\title{
OSCILLATORY MOTION CONTROL OF HINGED BODY USING CONTROLLER
}

\author{
Harshad P Patel ${ }^{1}$, R.C.Patel ${ }^{2}$ \\ ${ }^{1}$ M.E.- $2^{\text {nd }}$ Year, ${ }^{2}$ Associate professor, Instrumentation \& Control Department L.D.College of Engineering \\ Ahmedabad,India, hartel70@rediffmail.com,profrcpatel@yahoo.com
}

\begin{abstract}
Due to technological revolution, there is change in daily life usuage of instrument \& equipment.These usuage may be either for leisure or necessary and compulsory for life to live. In past there is necessity of a person to help other person but today`s fast life has restricted this helpful nature of human. This my project will helpful eliminate such necessity in certain cases. Oscillatory motion is very common everywhere. But its control is not upto now deviced tactfully. So it is tried to automate it keeping mind constraints such as cost, power consumption, safety,portability and ease of operating. Proper amalgamation of hardware and software make project flexible and stuff. The repetitive, monotonous and continuous operation is made simple by use of PIC microcontroller. There does not existing prototype or research paper on this subject. It probable first in it type.
\end{abstract}

\section{INTRODUCTION}

Hinged body means

- Any substance that is attached to solid link one end like camera, chair, cradle , ball, boat and cage.

$\square$ Other end of it is connected to oscillating shaft rigidly.Oscillatory

$\square$ means changing place at certain angle and distance vertically which are variable.

$\square$ Rotation frequency is variable.

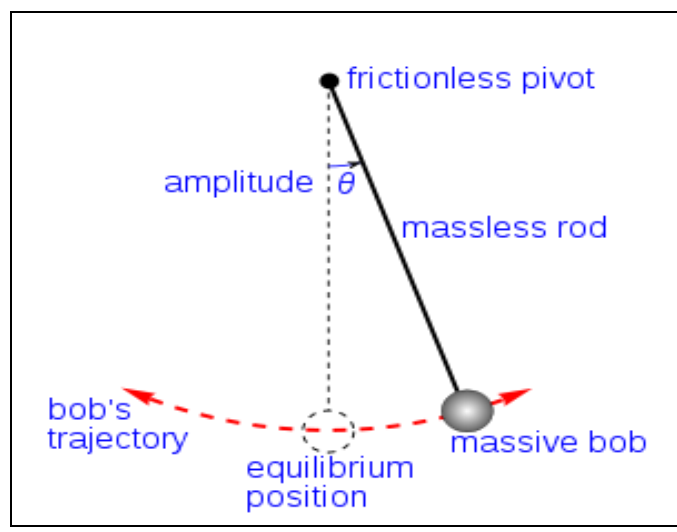

Fig.-1 Basic Pendulum

\section{PERIOD OF OSCILLATION}

The period of a pendulum gets longer as the amplitude $\theta 0$ (width of swing) increases. The true period of a pendulum gets longer as the amplitude $\theta 0$ (width of swing) increases. The period

$$
T \approx 2 \pi \sqrt{\frac{L}{g}}
$$

where $\mathrm{L}$ is the length of the pendulum and $\mathrm{g}$ is the local acceleration of gravity

\section{THE MODEL}

Assume that a pendulum of length 1 has a bob of mass m.Figure 1 shows the pendulum's position at some time $t$, with the variable $\mathrm{x}(\mathrm{t})$ denoting the angle that the pendulum makes with the vertical axis at that time. The angle is measured in radians. The pendulum's acceleration is proportional to the angular displacement from vertical; we model the drag due to friction with the air as being proportional to velocity. This yields a second-order ordinary differential equation (ODE) for $\mathrm{t} \geq \square 0$ :, (1)

$\operatorname{mld} 2 \mathrm{x} / \mathrm{dt} 2+\mathrm{cdx} / \mathrm{dt}+\mathrm{mg} \sin \mathrm{x}(\mathrm{t})=\mathrm{u}(\mathrm{t})$

where

$\mathrm{g}$ is the gravitational acceleration on an object at the earth's surface

$\mathrm{c}$ is the damping (or frictional) constant.

$\mathrm{u}(\mathrm{t})$ defines the external force applied to the pendulum.

In this project, we consider what happens in three cases: no external force, constant external force driving the pendulum to a final state, and then a force designed to minimize the energy needed to drive the shaft ( arm ) from an initial position to an angle xf. 


\section{THE SHAFT (ARM) STABILITY AND CONTROLLABILITY}

The solution to Equation 1 depends on relations among m, c, $\mathrm{g}$, and $\mathrm{u}(\mathrm{t})$ and ranges from fixed amplitude oscillations for the undamped case $(c=0)$ to decays (oscillatory or strict) for the damped case $(c>0)$. Unfortunately, there is no simple analytical solution to the pendulum equation in terms of elementary functions unless we linearize the term $\sin (x(t))$ in Equation 1 as $\mathrm{x}(\mathrm{t})$, an approximation that is only valid for small values of $\mathrm{x}(\mathrm{t})$. Despite the linear approximation's limitations, the linearization helps us find analytical solutions and also apply the results of linear control theory to the specific problem of robot arm control. To control the arm in a reasonable way, the system must be stable. Problem 1 considers the stability of a simpler model, valid for small oscillations. Equation 1's stability is more difficult to analyze than the stability of the linearized approximation to it. Liapunov's stability occurs when the total energy of an unforced (or undriven),dissipative mechanical system decreases as the system state evolves in time. Therefore, the state vector $\mathrm{yT}=[\mathrm{x}(\mathrm{t}), \mathrm{dx}(\mathrm{t}) / \mathrm{dt}]$ approaches a constant value (or steady state) corresponding to zero energy as time increases.According to Liapunov's formulation, the equilibrium point $\mathrm{y}=0$ of a system described by the equation $\mathrm{y}^{\prime} \square=\mathrm{f}(\mathrm{t}, \mathrm{y})$ is globally asymptotically stable if $\lim \mathrm{t}->\infty \square$ $\& \square \mathrm{y}(\mathrm{t})=0$ for any choice of $\mathrm{y}(0)$. Let $\mathrm{y}^{\prime} \square=\mathrm{f}(\mathrm{t}, \mathrm{y})$ and let $\mathrm{y}$ be a steady-state solution of this differential equation. Terminology varies from text to text, but we will use these definitions:

A positive definite Liapunov function $v$ at $-\mathrm{y}(\mathrm{t})$ is a continuously differentiable function into the set of nonnegative numbers. It satisfies

$$
\mathrm{v}(-\mathrm{y})=0, \mathrm{v}(\mathrm{y}(\mathrm{t}))>0 \text {, and } \mathrm{dv}(\mathrm{y}(\mathrm{t})) / \mathrm{d}(\mathrm{t})<0
$$

for all $\mathrm{t}>0$ and all $\mathrm{y}$ in a neighborhood of $-\mathrm{y}$.

An invariant set is a set for which the solution to the differential equation remains in the set when the initial state is in the set. This version of the Liapunov theorem3 for global asymptotic stability guides our analysis:

Theorem 1. Suppose $\mathrm{v}$ is a positive definite Liapunov function for a steady-state solution $-\mathrm{y}$ of $\mathrm{y}^{\prime} \square=\mathrm{f}(\mathrm{t}, \mathrm{y})$. Then $-\mathrm{y}$ is stable. If in addition

$\{\mathrm{y}: \mathrm{dv}(\mathrm{y}(\mathrm{t})) / \mathrm{dt}=0\}$ contains no invariant sets other than $-\mathrm{y}$, then $-\mathrm{y}$ is asymptotically stable.

Finding a Liapunov function for a given problem can be difficult, but success yields important information. For unstable systems, small perturbations in the application of the external force can cause large changes in the behavior of the equation's solution and, thus, to the pendulum's behavior, so the robot arm might behave erratically. Therefore, in practice, we must ensure that the system is stable

\section{NUMERICAL SOLUTION OF INITIAL VALUE PROBLEM}

Next, we develop some intuition for the behavior of the original and the linearized models by comparing them under various experimental conditions. For the numerical investigations assume that $\mathrm{m}=1 \mathrm{~kg}, 1=1 \mathrm{~m}$, and $\mathrm{g}=9.81$ $\mathrm{m} / \mathrm{sec} 2$, with $\mathrm{c}=0$ for the undamped case and $\mathrm{c}=0.5 \mathrm{~kg}$ $\mathrm{m} / \mathrm{sec}$ for the damped case. First we investigate the effects of damping and of applied forces.

\section{Missing Data: Solution of the Boundary Value Problem}

we solved the initial value problem, in which values of $\mathrm{x} \square$ and $\mathrm{dx} / \mathrm{dt}$ were given at time $\mathrm{t}=0$. In many cases, we don't have the initial value for $\mathrm{dx} / \mathrm{dt}$, because this value might not be observable. The missing initial condition prevents us from applying standard methods to solve initial value problems. Instead, we might have the value $x(t B)=x B$ at some other time tB. Next we investigate two solution methods for this boundary value problem: the shooting method and the finitedifference method. The idea behind the shooting method is to guess at the missing initial value $\mathrm{z}=\mathrm{dx}(0) / \mathrm{dt}$, integrate Equation 1 using our favorite method, and then use the results to improve the guess. To do this systematically, we use a nonlinear equation solver to solve the equation $\mathrm{p}(\mathrm{z})=\mathrm{xz}(\mathrm{tB})-$ $\mathrm{xB}=0$, where $\mathrm{xz}(\mathrm{tB})$ is the value reported by an initial value problem ODE solver for $\mathrm{x}(\mathrm{tB})$, given the initial condition $\mathrm{z}=$ $\mathrm{dx}(0) / \mathrm{dt}$

The finite-difference method is an alternate method to solve a boundary value problem. Choose a small time increment $b>0$ and replace the first derivative in the linearized model of Equation 1 by

$\mathrm{dx}(\mathrm{t}) / \mathrm{dt}=\{\mathrm{x}(\mathrm{t}+\mathrm{b})-\mathrm{x}(\mathrm{t}-\mathrm{b})\} / 2 \mathrm{~b}$

and second derivative by

$\mathrm{d} 2 \mathrm{x}(\mathrm{t}) / \mathrm{dt} 2=\{\mathrm{x}(\mathrm{t}+\mathrm{b})-2 \mathrm{x}(\mathrm{t})+\mathrm{x}(\mathrm{t}-\mathrm{b})\} / \mathrm{b} 2$

Let $\mathrm{n}=\mathrm{tB} / \mathrm{b}$, and write the equation for each value $\mathrm{xj}=\mathrm{x}(\mathrm{jb}), \mathrm{j}$ $=1, \ldots, \mathrm{n}-1$. The boundary conditions can be stated as $\mathrm{x} 0=$ $\mathrm{x}(0), \mathrm{xn}=\mathrm{xB}$. This method transforms the linearized versionof the second-order differential Equation 1 to a system $\mathrm{f} n-1$ linear equations with $\mathrm{n}-1$ unknowns. Assuming the solution to this linear system exists, we then use our favorite linear system solver to solve these equations.

\section{CONTROLLING THE PENDULUM ARM}

we investigate how to design a forcing function that drives the robot arm from an initial position to some other desired position with the least expenditure of energy. We measure energy as the integral of the absolute force applied between 
time 0 and the convergence time tc when the arm reaches its destination.

we studied one simple mathematical model of a robot arm. The numerical solution couples techniques borrowed from linear algebra, ordinary differential equations, optimization, and control theory. Control of our system involves cost tradeoffs: energy versus time of convergence. It's worth noting that stability and control studies of most physical systems (such as underground seepage, muscle movement, and combustion reactions) require a combination of analytical and computational tools, even for quite simple mathematical models.

\section{SYSTEM MODEL DEVELOPMENT}

This system is described by a second-order ordinary differential equation (ODE) for $\mathrm{t} \geq 0$ :,

$$
\text { mld } 2 x / d t 2+c d x / d t+m g \sin x(t)=u(t)
$$

$1=$ length of a pendulum $=21 \mathrm{~cm}=0.21 \mathrm{~m}$ for bearing mounted shaft

mounted shaft

$$
=18 \mathrm{~cm}=0.18 \mathrm{~m} \text { for bush }
$$

$\mathrm{m}=$ mass of a bob $/$ hinged body $=75$ gram $=0.075 \mathrm{~kg}$.

$\mathrm{g}=$ gravitational acceleration $=9.81 \mathrm{~m} / \mathrm{sec}$

$\mathrm{c}=$ damping (or frictional) constant

$\mathrm{u}(\mathrm{t})=$ external force ( unit impulse) applied to the pendulum

Therefore

$$
0.0157(\mathrm{~d} 2 \mathrm{x} / \mathrm{dt} 2)+\mathrm{c}(\mathrm{dx} / \mathrm{dt})+0.735 \sin (\mathrm{x}(\mathrm{t}))=\mathrm{u}(\mathrm{t})
$$

for $\zeta=0.1 \quad$ system to be underdamped ( for bush mounted shaft)

$$
\zeta=0.04 \text { for bearing mounted shaft }
$$

$$
\zeta=\mathrm{c} / 2(\mathrm{mk}) 1 / 2
$$

will give

$$
\mathrm{c}=0.0215 \text { (bush) and } \mathrm{c}=0.0215 \text { (bearing) }
$$

and small displacement $\sin x(t)=x(t)$

So system equation / model is

$$
\begin{aligned}
0.0157(\mathrm{~d} \mathrm{2x} / \mathrm{dt} 2)+ & 0.0215(\mathrm{dx} / \mathrm{dt})+0.735(\mathrm{x}(\mathrm{t}))=\mathrm{u}(\mathrm{t}) \\
& (\text { bush mounted }) \\
0.0157(\mathrm{~d} \mathrm{2x} / \mathrm{dt} 2)+ & 0.0083(\mathrm{dx} / \mathrm{dt})+0.735(\mathrm{x}(\mathrm{t}))=\mathrm{u}(\mathrm{t}) \\
& (\text { gear mounted })
\end{aligned}
$$

we get $\mathrm{M}=0.0157 \mathrm{~F}=0.0215$ and $\mathrm{K}=0.735$

From above equation value of natural frequency oscillation and damped frequency of oscillation can be calculated

$$
\mathrm{WN}=(3 \mathrm{~K} / 2 \mathrm{M}) 1 / 2=(2.2 / 0.0314) 1 / 2=(70.06) 1 / 2=8.37
$$

$2 \pi \mathrm{FN}=1.087$ therefore $\mathrm{FN}=1.33 \mathrm{~Hz}$

\subsection{MATLAB SIMULATION RESULT (BEARING MOUNT)}

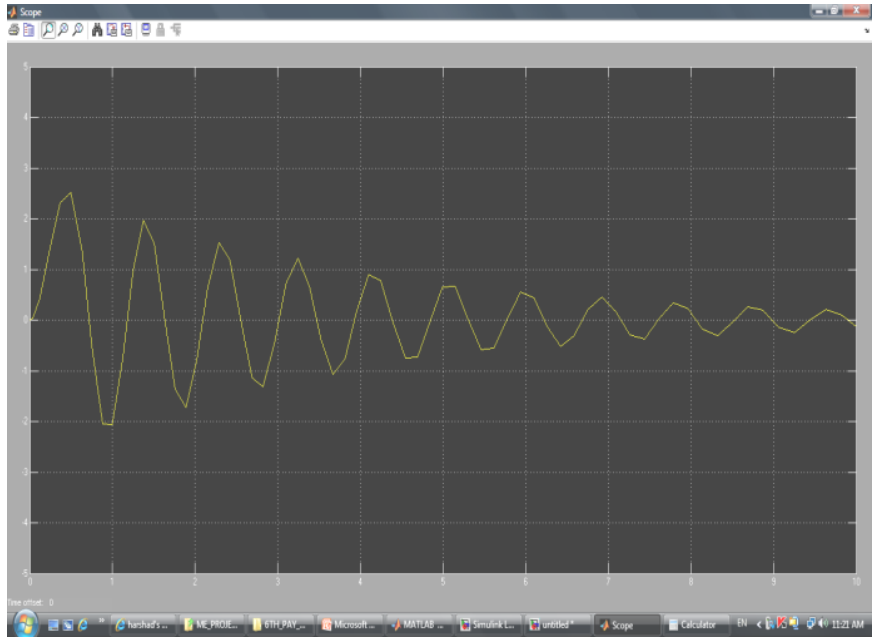

Fig. 7.1 2nd Order System bearing mount Response

\subsection{MATLAB SIMULATION RESULT (BUSH MOUNT)}

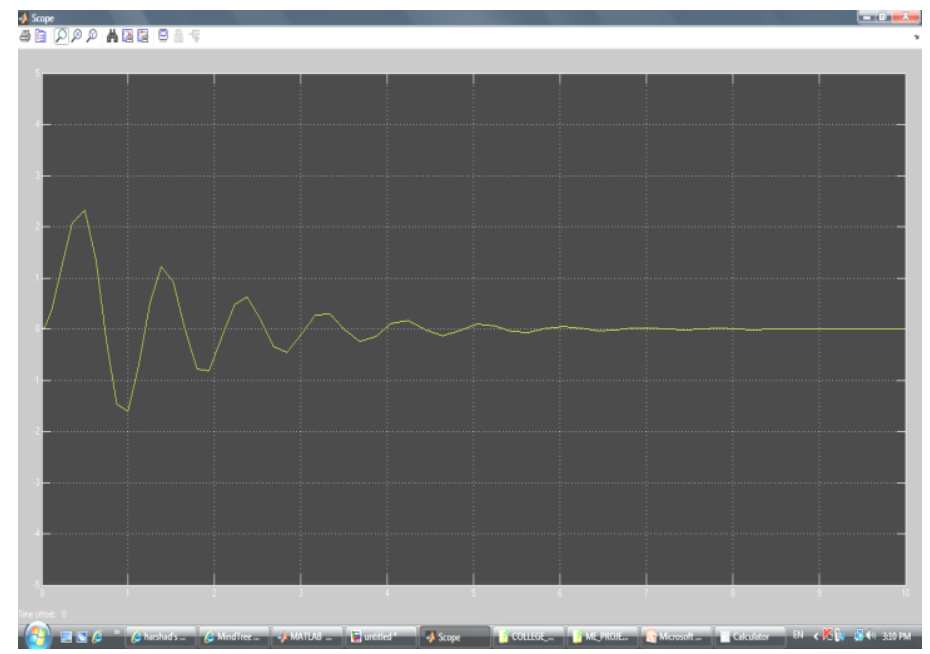

Fig. 7.2 2nd Order System bush mount Response

Compare this equation with standard 2 nd order equation

$$
M(d x 2 / d t 2)+F(d x / d t)+d x / d t=u(t)
$$




\section{BLOCK DIAGRAM OF SYSTEM}

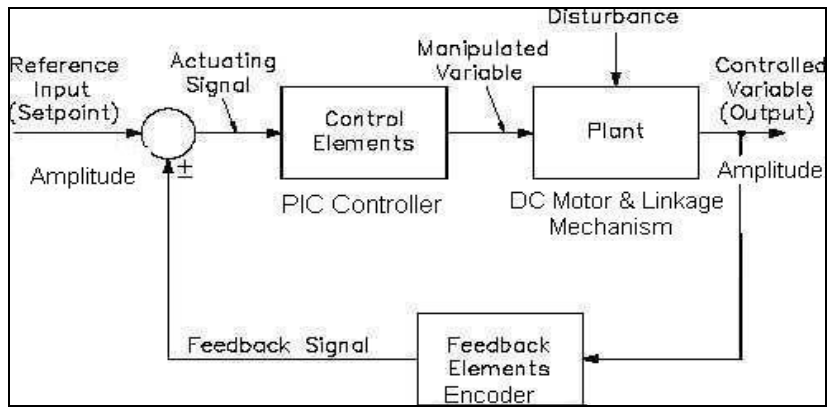

\section{METHOD OF COUPLING}

1. Rigid coupling

2. Flexible coupling

\subsection{RIGID COUPLING}
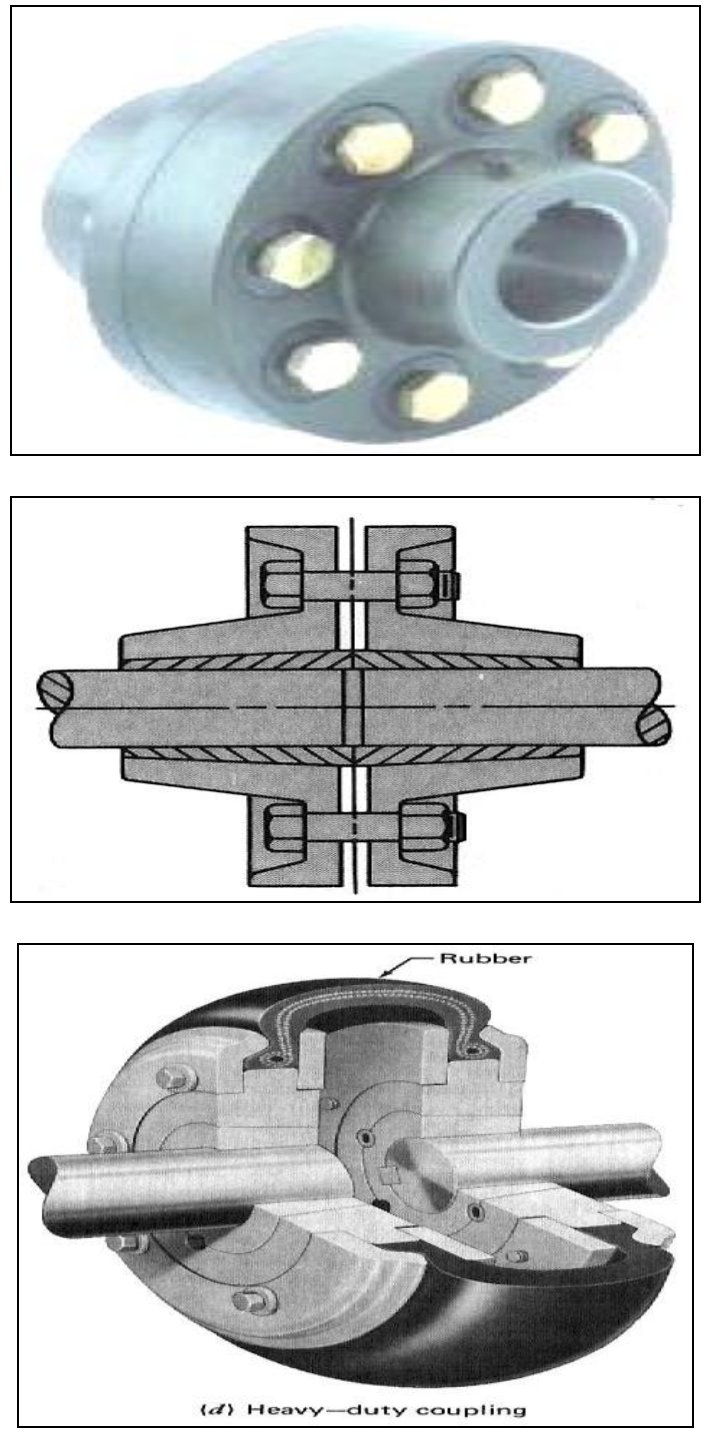

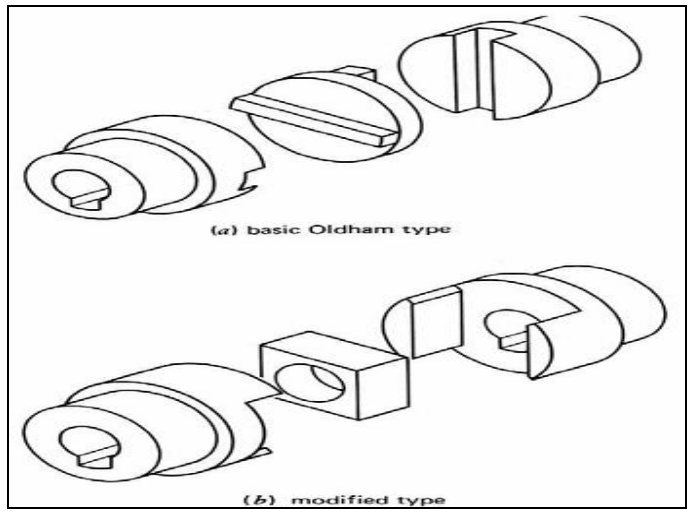

Fig -3 Types of rigid coupling

Rigid couplings which do not allow for any shaft misalignment. Top: The coupling on the left uses square keys to transmit torque,the one on the right depends on compressing rubber sleeves and may therefore allow slip to occur if the machine becomes overloaded. Lower: Couplings in the lower group are in two halves and are able to be slipped over the two shafts after machines have been placed in position, whereas those in the top group have to be slide onto their shafts before the machines are positioned.

\subsection{FLEXIBLE COUPLING}

\subsubsection{Belt Drives}

A belt drive is used to transmit power from one shaft to another. The drive is transmitted by a continuous flexible belt which runs on pulleys mounted on the two shafts. Belt drives have a number of advantages in some circumstances, including the ability to transmit power between shafts whose centers are some distance apart. Speed changes are also readily achieved, installation and maintenance costs are relatively low, and no lubrication is needed.

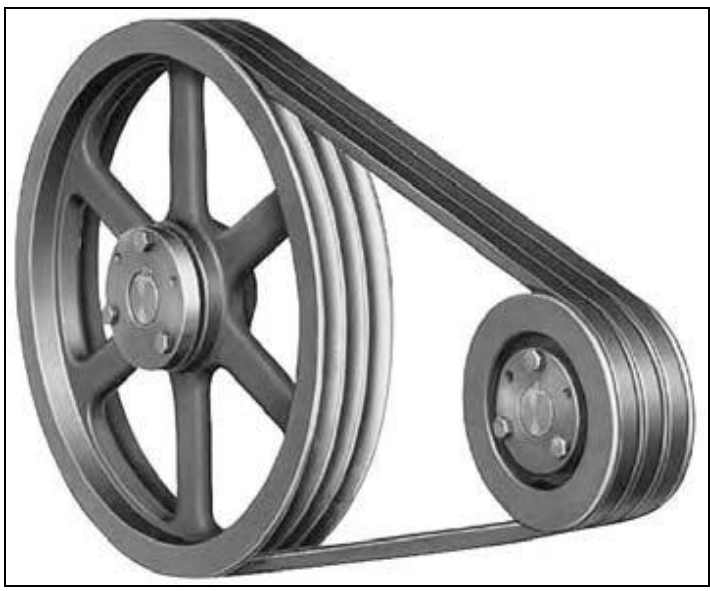

Fig.4 Belt drives 


\section{Characteristics of belt drives}

Belt drives are suitable for medium to long centre distances. Compare with gears, which are suitable only for short centre distances.

Belt drives have some slip and creep (due to the belt extending slightly under load) and therefore do not have an exact drive ratio.

$\square$ Belts provide a smooth drive with considerable ability to absorb shock loading.

$\square$ Belt drives are relatively cheap to install and to maintain. A well-designed belt drive has a long service life.

$\square$ No lubrication is required. In fact, oil must be kept off the belt.

$\square$ Belts can wear rapidly if operating in abrasive (dusty) conditions.

\subsubsection{Chain Drives}

There are similarities between chain drives and belt drives, and many of the operating principles apply to both. The analysis of speed and torque relationships developed above for belts apply equally to chain drives, always working with pitch line velocities or their equivalent. A simple roller chain drive used in an automotive application. The chain and sprockets would be encased within a cover or housing as part of the engine to maintain cleanliness and to provide lubrication. In this layout, shaft centres are fixed. Note the use of a chain tensioner to prevent excessive deflection or "whipping" of the slack side of the chain.

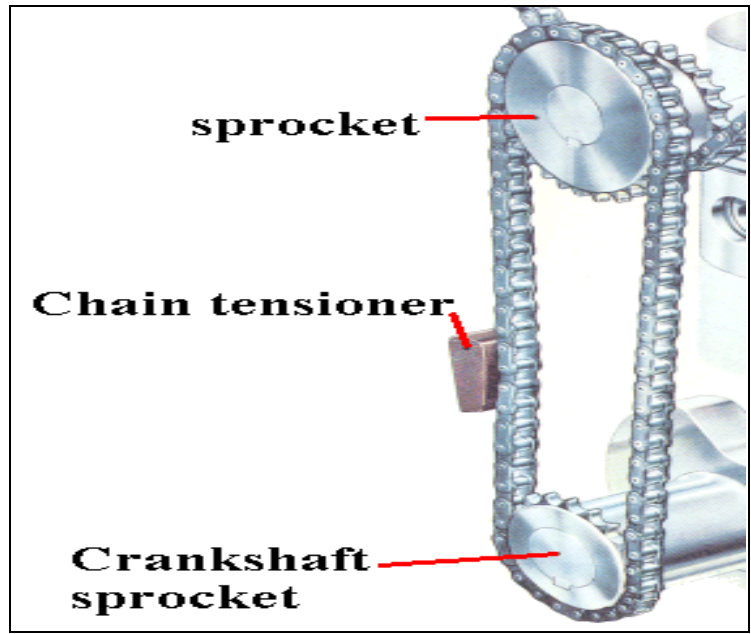

Fig.-5 Chain drive

\section{Characteristics of chain drives}

Chains provide a positive drive suitable for use where timing/phasing is required. Before the development of timing belts, chains were frequently used for driving the camshafts of motor car engines.

$\square$ Chains transmit shock loading, whereas belts tend to absorb any shock loading which may occur.
The speedratio is determined by the number of teeth on the two chain wheels or sprockets, although calculations based on sprocket pitch diameters and pitch line velocities are equally valid.

$\square$ A chain drive is more costly to set up than a belt drive, but has a long life.

$\square$ Very high torques may be transmitted by chains, beyond the capacity of belt drives. The drive does not depend on friction.

$\square$ Chains generally require lubrication and a heavy duty chain drive may require a sealed housing incorporating either bath or jet lubrication, thereby increasing cost.

Abrasive material rapidly destroys a chain drive.

It is best not to use chain drives on very long centre distances because the long lengths of chain tend to "whip".

\subsubsection{Cam and Follower}

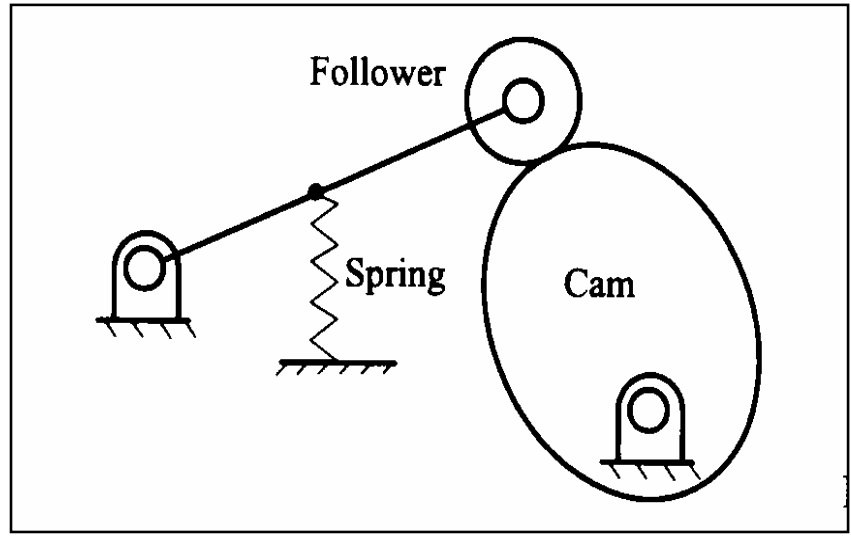

Fig-6 Elements of Cam-follwer system

Cams are used for essentially the same purpose as linkages, that is, generation of irregular motion. Cams have an advantage over linkages because cams can be designed for much tighter motion specifications. In fact, in principle, any desired motion program can be exactly reproduced by a cam. Cam design is also, at least in principle, simpler than linkage design, although, in practice, it can be very laborious. Automation of cam design using interactive computing has not, at present, reached the same level of sophistication as that of linkage design.A cam and follower system is system/mechanism that uses a cam and follower to create a specific motion. The cam is in most cases merely a flat piece of metal that has had an unusual shape or profile machined onto it. This cam is attached to a shaft which enable it to be turned by applying a turning action to the shaft. As the cam rotates it is the profile or shape of the cam that causes the follower to move in a particular way. The movement of the follower is then transmitted to another mechanism or another part of the mechanism.

If we examine the image below we can see how the profile of the cam imparts a particular motion on the follower. 


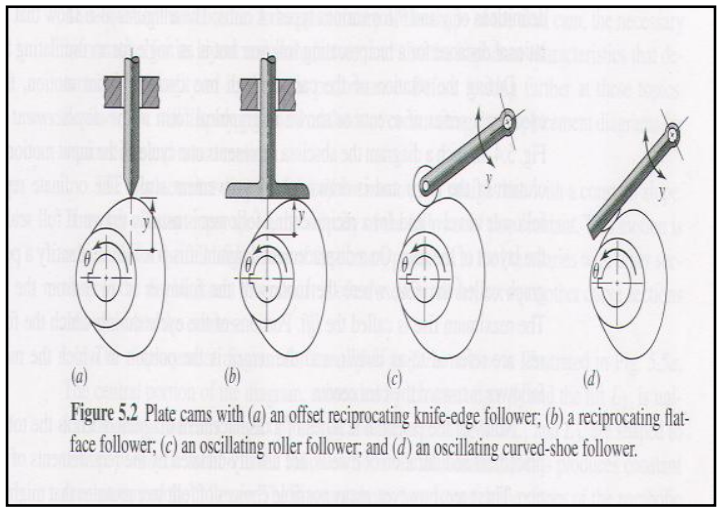

Fig.-7 Types of cam \& follower

\section{HORIZONTAL SHAFT MOUNTING}

\section{METHODS}

There are two type of basic methods are used for shaft mounting.

10.1. Bearing supported

10.2. Bush supported

\subsection{Bearing supported}

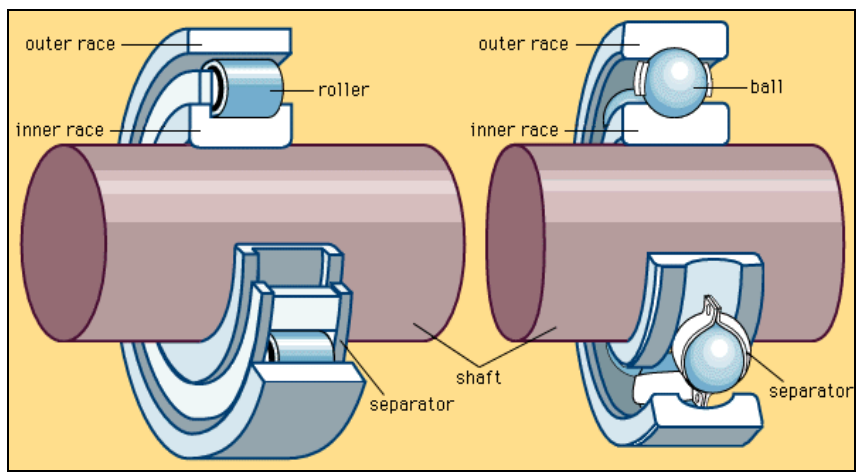

Fig.8 Bearing supported shaft

\subsection{Bush supported}

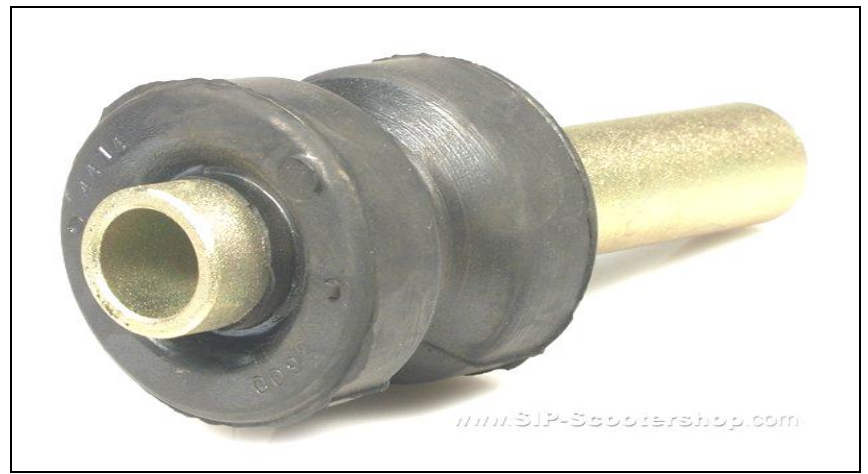

Fig.-9 Bush supported shaft

\subsection{Different type and size of bush}

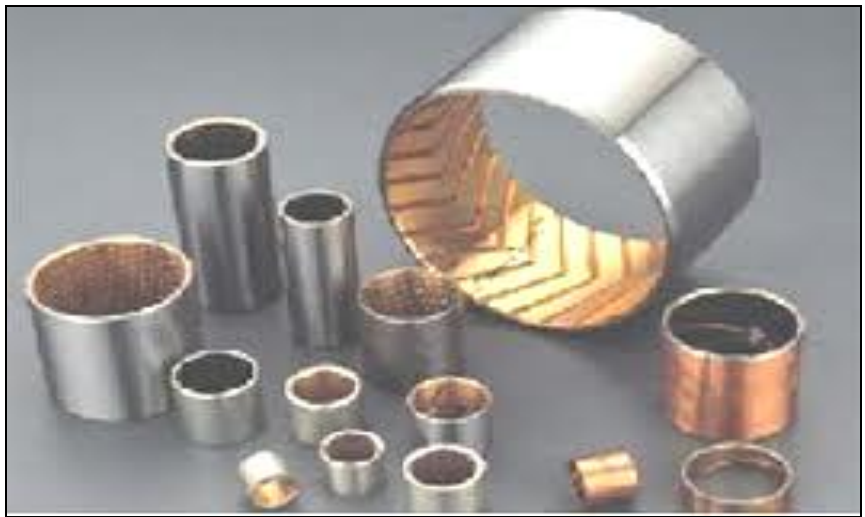

Fig.10 Types of Bushes

\subsection{MATLAB SIMULATION RESULT (BEARING}

\section{MOUNT)}

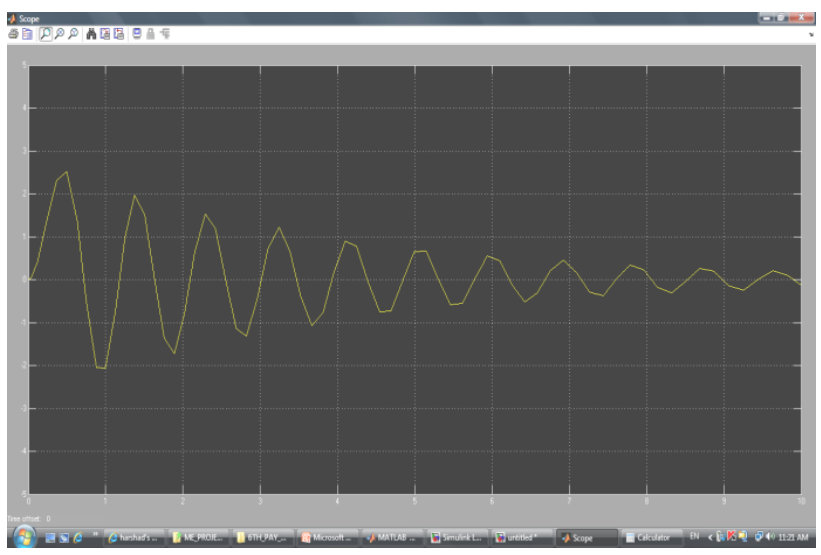

Fig. 11 2nd Order System bearing mount Response

\subsection{MATLAB SIMULATION RESULT (BUSH MOUNT)}

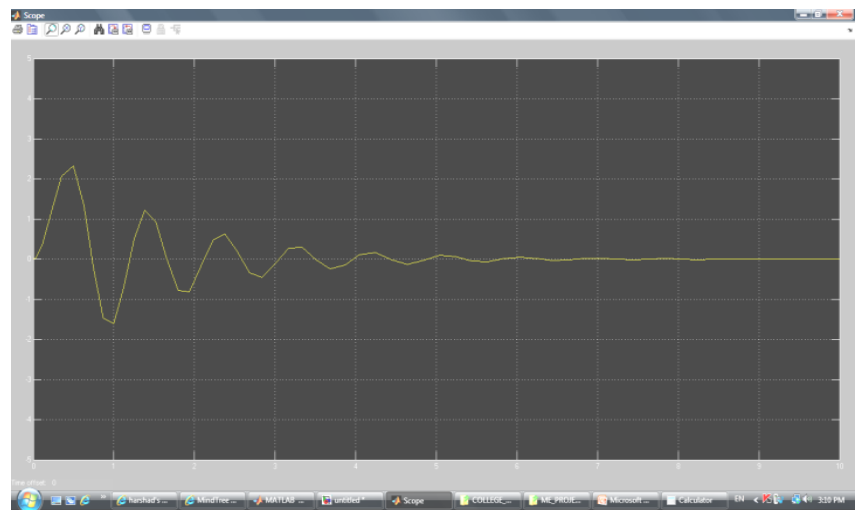

Fig. 12 2nd Order System bush mount Response 


\subsection{VARIOUS METHOD OF SHAFT COUPLING} RESPONSE TO UNIT IMPULSE

10.3.1 Rigidly coupled shaft Response.
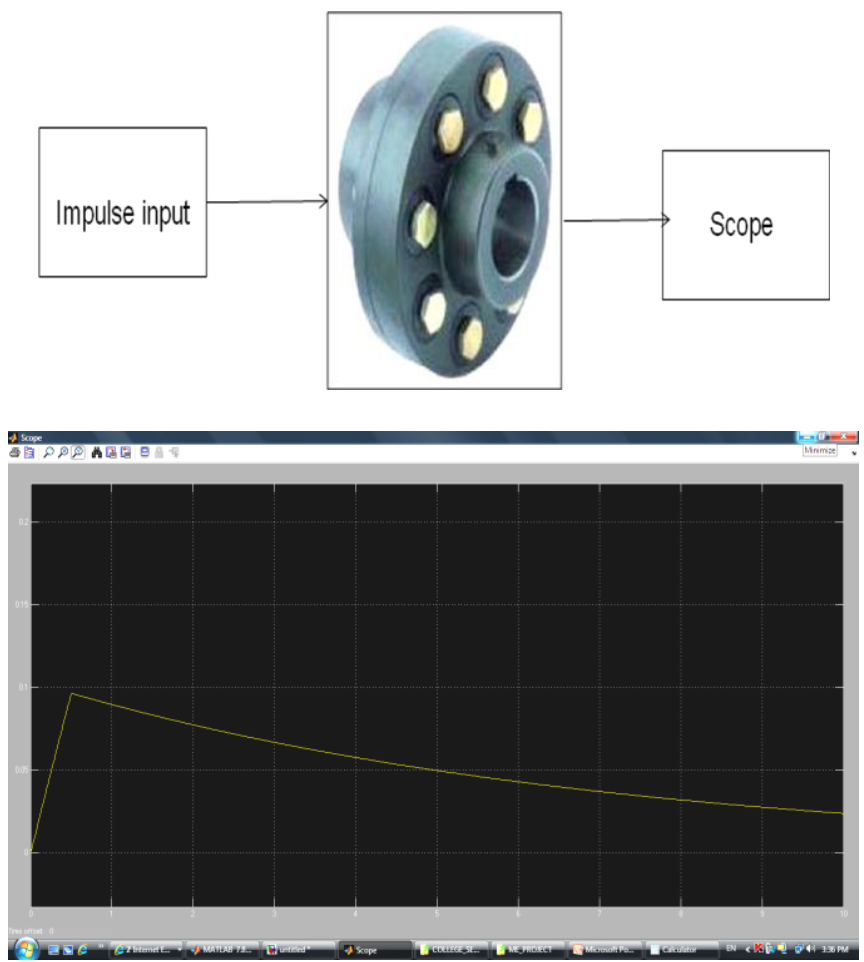

10.3.2 Chain / Belt coupled shaft Response
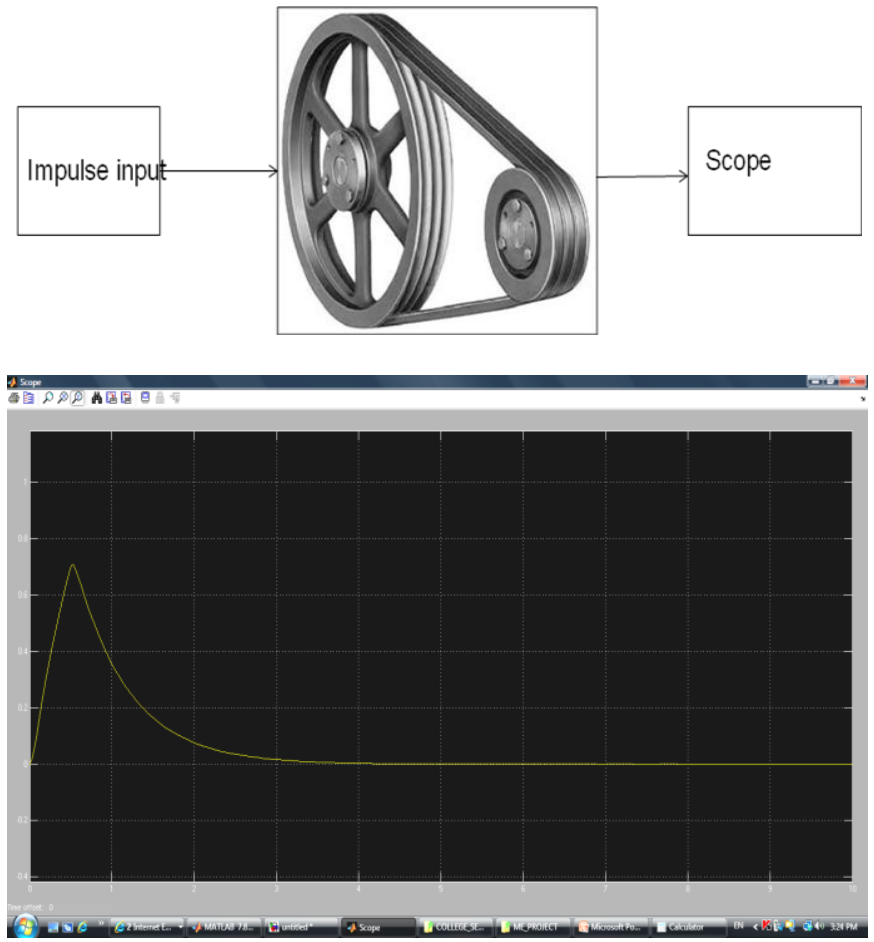

10.3.3 Gear coupled shaft Response.

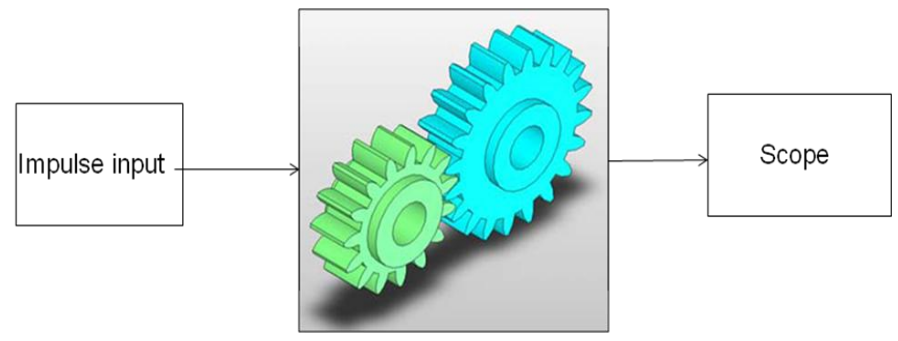

10.3.4 Cam coupled shaft Response.
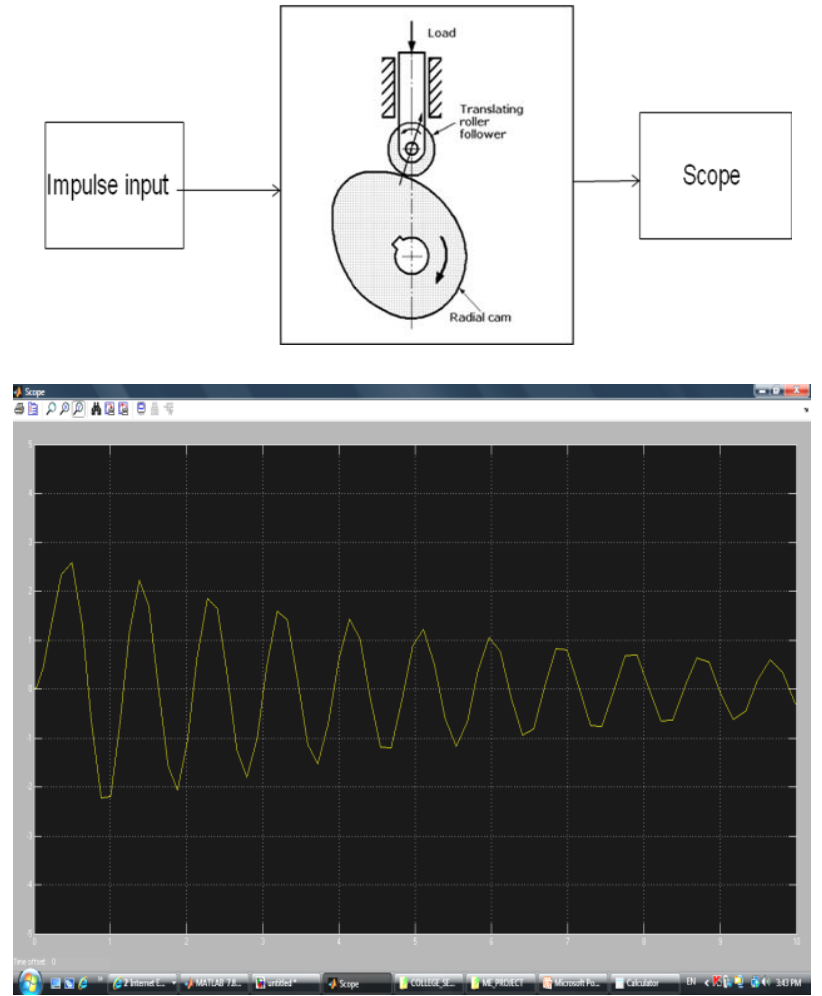

11. SYSTEM IMPLEMENTED

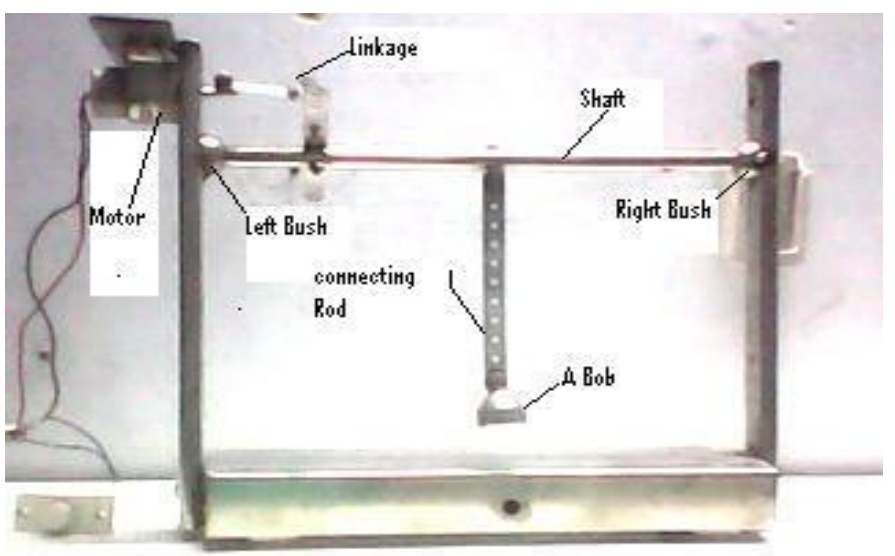




\section{CONCLUSIONS}

It was found that the implementation of such a system is better suited to for deep sleep of infants which causing higher growth \& make his/her mother free for other work, to smoothen picture \& serial director's shooting work,to discontinuous heating of substances in industry,to handicapped (specifically without two legs),old person and sick person to swing on their own and at lastto people to get rid of tyranny heat of summer season economically.

\section{REFERENCES}

[1].Institute of Electrical and Electronics Engineers Cannon, B.L. "Magnetic Resonant Coupling As a Potential Means for Wireless Power Transfer to Multiple Small Receivers."Power Electronics, IEEE Transactions on 24.7 (2009): 1819-1825. () 2009

[2].Mechanism Design, Analysis and Synthesis by Erdman and sander, fourth edition, Prentice- Hall, 2001,

[3].Machines and Mechanisms by Uicker, Pennock and Shigley, third edition, Oxford, 2002.Machines and Mechanisms by Myszka, Prentice-Hall, 1999

[4].www.SIP-Scootershop.com

[5].www.hondaforeman.com

[6].Kajima, H.; Masahiro Doi; Hasegawa, Y.; Fukuda, T.; , "Energy Based Swing Control of a Brachiating Robot," Robotics and Automation, 2005. ICRA 2005. Proceedings of the 2005 IEEE International Conference on , vol., no., pp. 3670- 3675, 18-22 April 2005

[7].K.J. Astrom , K. Furuta,"Swinging up a pendulum by energy control" Automatica 36 (2000) 287-295

[8].Lu, Cheng-Hsing; Luo, Ching-Hsing; Chen, Yung-Jung; Yeh, Tsu-Fuh;, , "An automatic swinging instrument for better neonatal growing environment," Review of Scientific Instruments , Vol. 68, no. 8, pp. 3192-3196, Aug 1997

[9].Piccoli, B. \& Kulkarni, J . "Pumping a swing by standing and squatting: do childrenPump time optimally?"Control Systems, IEEE, 2005,25,48 - 56

[10].Sato, M.; Toda, M.; , "Motion control of an oscillatorybase manipulator in the global coordinates," Control and Automation, 2009. ICCA 2009. IEEE International Conference on , vol., no., pp.349-354, 9-11 Dec. 2009. 